\title{
Proximal Interphalangeal Joint 3 of the Hand
}

National Cancer Institute

\section{Source}

National Cancer Institute. Proximal Interphalangeal Joint 3 of the Hand. NCI Thesaurus.

Code C114195.

A ginglymoid (hinge) synovial joint within the third digit of the hand connecting the proximal and middle phalanges. 